\title{
Agriculture Ontology for Sustainable Development in Nigeria
}

\author{
Emmanuel Ukpe \\ School of Information Technology \& ComputingAmerican University of NigeriaYola Bypass, PMB 2250, Yola, \\ Adamawa State, Nigeria
}

\begin{abstract}
Nigeria, a country of more than 160 million people; also, the biggest oil exporter in Africa [1] Nigeria with her oil wealth, food security, and unemployment remains a serious problem. Shortage and increase in food prices has raised serious concerns regarding food and nutrition security across the country. Logical action is required to support vulnerable citizens (about 90\%) cope with increases in food prices; assist farmers to quickly respond to the "opportunity" presented in an attempt to mitigate food security. To this end, this paper presents a proactive strategy for food security. An ontology-driven information retrieval system for agriculture cross languages search engine is proposed, a Nigeria Agricultural Ontology (NAO). Ontology, not only to structure and standardize agricultural terminology, but to provide information which would assist farmers to facilitate agricultural production, reduce dependence on food imports, revitalized agricultural sector, create employment andthereby attained food security for Nigeria.
\end{abstract}

Keywords: agriculture, food security, thesaurus, ontology

\section{Introduction}

Ontology has always faced a lotof insurmountablecontroversy especially when people are trying to understand its meaning. Food and agriculture organization (FAO) have always used this to show the contribution that it would make to improve the societal agricultural and food sector for sustainable development to all nations that are member to FAO [2].This paper will focus on the method through which by use of ontology, Nigeria citizens, and most especially the farmers would be able to organize information for application to enhance productivity in terms of agriculture and food products. Ontology is all about information dissemination through the right channels, and the right people when they most want this information to make a decision, and to take on the best course of action that should be taken. Information is extremely crucial element that could be used to drive decision making a cinch.

The main problems facing ontology is the process through which information retrieval is done. Organization of information for use on agriculture has also been too much of a hurdle. On the other hand, machines that will be used do not accommodate for legacy systems.

\section{Review Of Literature on Agriculture Ontology}

Ontology could be referred to as a directory structure on a hard disk. In the definition of the word ontology, so that one may fully understand what it means, there has been an outline that says that human beings could survive without ontologies. This is because they have another sixth sense which directs them in all actions that they take. This is also referred to as intuition. On the other hand, machines such as computer have no sixth sense, and they rely on data fed onto them.This data that are fed onto these machines is ontology. Since humans cannot extent intuition into agriculture, ontology is the way to go to ensure crop growth monitoring.

According to [3], ontology is a formal representation of concepts which is knowledge within a domain. Ontologyalso tries to getinterlink between different concepts and it is mainly used to support the reasoning mechanism. Agricultural ontology standardized agricultural concepts in multiple languages so that it may be used for more systems in the agricultural domain. The main purpose of agricultural ontology is attaining more interoperability in the agricultural systems. Incorporation of these concepts as it is useful in assisting attainment and retrieval of bibliographical resources in the agricultural sector. The main purpose of the ontology is to assist players, and other stakeholders that are involved to make use of facts available for practical choices, such as crops that should be grown in specific sectors and how they will do well.

In agriculture,the use of ontology is seen to be extremely valuable as it makes use of concepts by relating them, identifying what these concepts mean, and evaluating any other component or information that needs to be used in relation to these concepts. Ontologies open a whole new helm of existence. Some of the most useful concepts that have been recommended to be embraced by agricultural ontology service are classification service which aims, at identifying the class divisions. There are otherssuch as meronymic, spatial, dependency, influence and other such as case relations, which aim to send out all concepts, and ideas that are related to the topic of interest without which there would not be things such as the relation. An instance where 
the use of ontology has been incorporated is when controlof pest diseases is done. One can monitor all the symptoms and then arrange them in and make correlations of what solution could be achieved[4].

According to [5] teaching machine to be intelligent is the key ingredients that would make ontologies extraordinarily useful. This is because a computer or machines will be able to respond specifically, to the most recent query such as, monitoring of activities that have been carried out most recently, and recommending controls or checks and balances. Another advantage of ontologies is through categorizing and organization of knowledge all over the web. Under machines being intelligent, Jain, Tedman \& Tedman thought of how it would be easier to searchinformation by category of full texts or data to producemeaningful results.

According to [6] ontology application is varied and goes onto many subsectors. The three main ways through which ontologies may be applied in agriculture is by building taxonomies through which there could be automatic classification through each taxa. The second manner, in which it could be applied, is through a common language processing, where concepts could be matched and queries be processed based on descriptions. A disease can be identified and treated through a single description. The language also makes it easy for identification of similar concepts that are related to the said ontology. The third application is aiding in information retrieval. This is done through automatic document sum up;where all documents or data that correlates to information that is being looked upon is seen as valuable and could assist in the research process.

\section{Rational For Nigerian Agriculture Ontology(Naos)}

According to [5] under agricultural sector, there are other well-known authorities in this field. These are FAO and AGROVOC thesaurus. In terms of ontology development, the AOS Concept Server is the pioneer conceptin offering services that are related to ontology. This is because it functions as a meansin structuringand formulating terminology, related to agriculture to be applied in the whole wide setting, and systems in the domain of agriculture. AOS has been presumed to be the main access point where all issues that are related to the agricultural sector would be developed. The concept will be built upon other ontologies that are in the sector of agriculture only that initially they had not been online, and it took long to process solution.

\section{A. The Nigerian Factor}

The need for Food security in Nigeria cannot be overemphasized [7], with everyday population growth, Nigeria needs to be at a position where her citizens are food-secure, not live in hunger or fear of starvation. It is the trust of this research that food security risk would be a matter of the past with agriculture ontology implementation. There are seven deficits in Nigerian agriculture. These are (i) modern farming knowledge deficit (ii) research and extension (technology) deficit; (iii) infrastructure deficit; (iv)credit, investment, land and irrigation deficit; (v) market deficit; (vi) diversification deficit; and (vii) institutions deficit [8]. Reforms starting with Nigeria Agriculture Ontology with cross languages search engine are needed to reduce these deficits in order to achieve food security and sustainability

\section{Development Process}

Ontology is a way of knowledge management, and it has had to evolve from the older setting that it once was to the new level that it is now. Initially during the pre-web stage, cards and catalogue were used to search for information. However, it still was a hectic endeavor; the second was the web which entailed the use of computer catalogue. Still it was hectic as information had to be scrutinized in batches. The most popular is the semantic web which focuses on metadata and portals which do the work of correlation.

The concept of the server through portals will allow for control of information in the field of agriculture. This is because ontology focuses on the various issues that arise in the field of agriculture. Online platform is the chosen form through which cooptation of the various segments will be done to ensure a model that builds up on previously stored information and knowledge. Selected maintainers such as FAO and AGROVOC [9] will ensure that the development ofthese information centers or ontologies in the domain of agriculture will be modeled and maintained for future use and reference. Users of the information, on the other hand, will be able to download subsections of the ontology and benefit from other services that come with this invention.

Development of ontology is subjected to three phases, which support the occurrences, and activities that are to take place in that particular ontology. The first step is requirement and analysis; in this case it may involve defining concepts in the domain. The second step entails designing and implementation. Once the concepts have been established, and different filing class have been indicated, the use of the ontology maybe applied to determine concepts and issues that are involved. The third step involves testing and validating the system. This is the first application of the system whether it will be used. Since it is an interactive system design, it accommodates for maintenance and steadybuildup of the system. This is the last and fourth stage. 


\section{A. Interactive System Design}

This server concept is also referred to as the thesaurus as it owns up all information that relates to Agriculture. It has also been seen as the starting point, where the oldersystemwhich is referred to as the current based system,is built upontheory based system which is the newest system. There are so many flaws that were carried by the older system, and needed to be resolved so as to develop a system that is less error prone, and will increase the scope of performance by ontologies [10].One significant advantage that is appended to concept server is the fact that it is quite extensible since it accommodates for information to be added upon the already gathered information anytime. This allows for users to be able to get more use of the system over and over again.

\section{Conclusion}

The most current based system Concept server could be referred to as a sum up of various related concept that tries to build upon the older systems. All these other concepts have their own uniqueness as they have multiple designations of languages.CS is a crucialaspect of agricultural ontology services, and it has quite a vital service it provides to users in the agricultural domain. This paper believes eradicating hunger, and extreme poverty requires knowledge of the ways in which these two inequalities interconnect. Food insecurity leads to hunger, which translates to malnourishment [11]. Thus, prevents Nigerian citizens from escaping demoralizing poverty as it diminishes their potential to earn a living, learn, nurture and support for their family. Agricultural ontology as the one proposed in this paper would go a long way preventing food insecurity, malnourishment, and unemployment. The plan ontology would provide necessary soil, planting, harvesting, crop diseases and pests management information that could lead to self-sufficiency and reduce external dependence on food import. Thus, ontology development would ensure sustainable development

\section{References}

[1] World Bank, (1986), Poverty and Hunger: Issue and Options for Food Security inDeveloping Countries Washington D.C.

[2] FAO (1998) "Urgent Action Needed to Combat Hunger as Number ofUndernourished in the World Increases" available on line @ www.fao.org.Retrieved on 15th December, 2012

[3] P. Papajorgji and F.Pinet (2012).New technologies for constructing complex agricultural and environment systems. Hershey, PA: Information Science Reference.

[4] C. Calero, F. Ruiz and M. Piattini (2006).Ontologies for software engineering and software technology. Berlin: Springer.

[5] L. Jain, R. Tedman and D. Tedman (2007).Evolution of teaching and learning paradigms in intelligent environment. Berlin New York: Springer.

[6] Sicilia. \&M. Lytras (2009).Metadata and semantics. New York: Springer.

[7] T. Benson (2004), Assessing Africa's Food and Nutrition Security Situation2020Africa Conference Brief 1 IFPRI

[8] J. A. Akinwumi (1989), Cooperatives: The Answer to Nigeria's ProductionConsumer Dilemma, Faculty Lecture Series No. 2. Faculty of Agriculture,University of Ibadan

[9] AGROVOC (2013) Agriculture Thesaurus. Retrieved June 2013 from http://www.fao.org/aims/ag_intro.htm

[10] P. Papajorgji andP.Pardalos (2008).Advances in modeling agricultural systems. New York London: Springer.

[11] World Health Organization (1985): Adopted from Hoddinott J. (2001) "Choosingoutcome indicators of household food security" in J. Hoddinott(2001) ed. FoodSecurity in Practice, Methods for Rural Development Projects, IFPRI pp. 31-45 